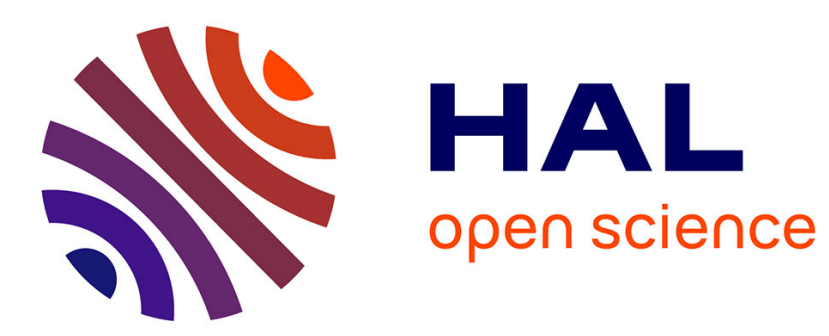

\title{
Compaction of a packing of hard spheres under horizontal shear
}

Maxime Nicolas, Paul Duru, Olivier Pouliquen

\section{To cite this version:}

Maxime Nicolas, Paul Duru, Olivier Pouliquen. Compaction of a packing of hard spheres under horizontal shear. Powders and Grains, 2001, Sendai, Japan. hal-01441048

\section{HAL Id: hal-01441048 \\ https://hal.science/hal-01441048}

Submitted on 25 Jan 2017

HAL is a multi-disciplinary open access archive for the deposit and dissemination of scientific research documents, whether they are published or not. The documents may come from teaching and research institutions in France or abroad, or from public or private research centers.
L'archive ouverte pluridisciplinaire HAL, est destinée au dépôt et à la diffusion de documents scientifiques de niveau recherche, publiés ou non, émanant des établissements d'enseignement et de recherche français ou étrangers, des laboratoires publics ou privés. 


\title{
Compaction of a packing of hard spheres under horizontal shear
}

\author{
M. Nicolas, P. Duru \& O. Pouliquen \\ IUSTI, Technop le de Ch teau-Gombert, 5 rue Fermi 13453 MARSEILLE cedex 13 France
}

\begin{abstract}
We present experimental results concerning the compaction of a granular assembly of glass spheres under periodic shear deformation. Results for a monodisperse set of spheres and a bidisperse set of spheres are presented
\end{abstract}

\section{INTRODUCTION}

It is well known that an assembly of identical rigid spheres poured in a box without caution arrange in a random packing with a volume fraction higher than 55 percent. The volume fraction of such a packing can be increased up to $63.66^{\circ} \%$ (according to Scott 1969) with tapping or shaking of the box. This limiting value is known as the maximum volume fraction of a random packing. Denser packings are obtained only if spheres arrange in an ordered structure. The maximum volume fraction is then $74.05^{\circ} \%$, corresponding to the face-centered cubic packing.

The evolution of a random loose packing to a random close packing has been experimentally studied by Knight et al (1995) and Nowak et al (1998). In this experiment the packing of hard spheres was submitted to a vertical vibration made of constant amplitude taps. Another compaction experiment (Pouliquen et al 1997) suggested that a horizontal shear could be reponsible for the compaction of an assembly of hard spheres. In that case, the compaction leads to crystalline arrangements of particles.

After a description of the experimental setup, we present results about the compaction of a monodisperse set of spheres (section 3). Section 4 presents the results for compaction of a two-sizes set of beads.

\section{EXPERIMENTAL SETUP}

Particles were spherical glass beads of 2 or $3 \mathrm{~mm}$ diameters. In order to prevent attriction effects between particles, beads were coated with viscous silicon oil. This coating did not affect the results for compaction but improved the lifetime of the glass beads.
The shear apparatus is drawn in figure ${ }^{\circ}$. The shear cell was parallelepiped, and the volume occupied by the beads was $10.5 \mathrm{~cm}$ high, $7.9 \mathrm{~cm}$ wide and $10.2 \mathrm{~cm}$ deep. The bottom of the cell was a flat plate attached to a horizontal linear displacement device driven by a stepper motor. The two mobile lateral walls were aluminum plates linked with two hinges to the bottom plate. These plates were covered with a thin plastic sheet to insulate the packing from metallic dust due to particle/wall friction. The front and back sides were glass plates fixed on the bottom plate. The granular packing was confined on the top by a rectangular plate mounted on a vertical rail.

The volume fraction of the packing was measured by recording the vertical position of the top plate with a linear position sensor. The accuracy of the sensor corresponded of a $2 \times 10^{-4}$ resolution in volume fraction.

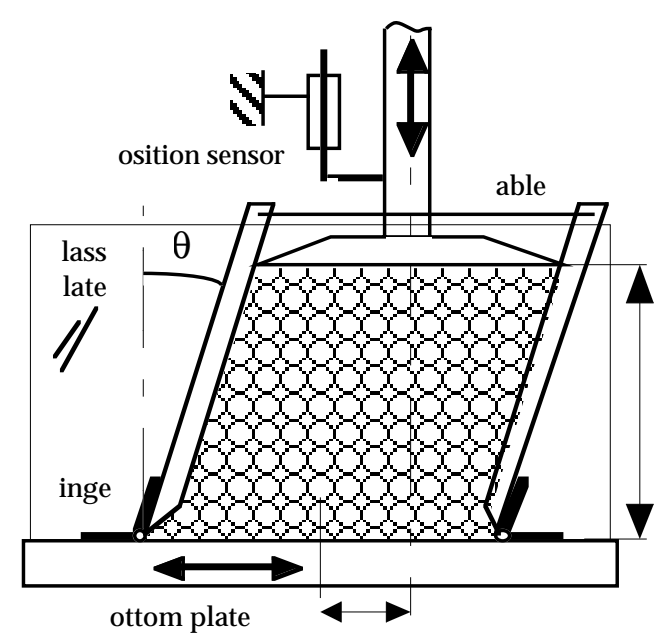

Figure 1. Sketch of the experimental setup. 
Before each experiment, the shear cell was filled with the lateral walls kept vertical. Beads were poured down through a hopper designed to ensure a homogeneous filling of the box section. The mean initial volume fraction obtained with this procedure was $60 \pm 1^{\circ} \%$. The periodic shear was then imposed. First, the lateral plates were inclined to an angle $+^{\circ} \theta$, then to an angle $-{ }^{\circ} \theta$, and finallywere put back in the vertical position. The volume fraction after such a cycle was recorded. The volume fraction could also be continously recorded with 325 measurements during a cycle.

\section{COMPACTION OF MONODISPERSE PACKINGS}

\subsection{Dilatancy properties}

A typical measurement of the volume fraction of the packing is shown in figure 2. This plot shows a superposition of two dynamics: a slow and monotonous increase of volume fraction $\phi$ and an oscillation corresponding to the dilatation of the packing during the shear cycle.

The oscillation amplitude $\delta \phi$ due to dilatation was observed to increase during the experiment. Figure 3 shows this amplitude plotted versus the average volume fraction (averaged over a cycle). Except for low volume fraction, a linear relation could be found between the dilatation amplitude and the volume fraction.

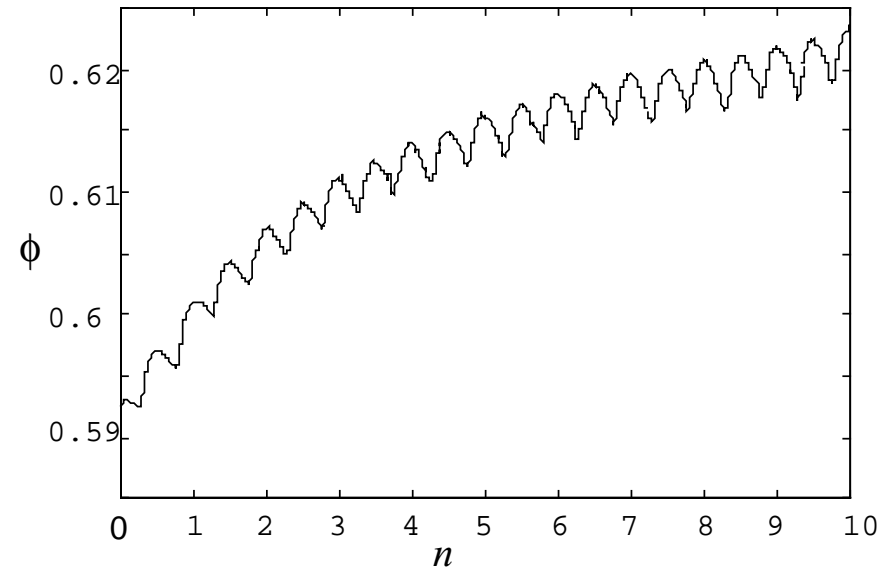

Figure 2. Volume fraction evolution from a random packing with a shear angle $\theta^{\circ}={ }^{\circ} 5.4 j . n$ is the elapsed number of cycle from the begining of the experiment.

\subsection{Long-time evolution of volume fraction}

The compaction by horizontal shear was observed to be a slow process. Figure 4 shows the volume fraction $\phi$ versus time for three different shear angles in semi-logarithmic scale. The volume fraction was still increasing even after a large number of cy-

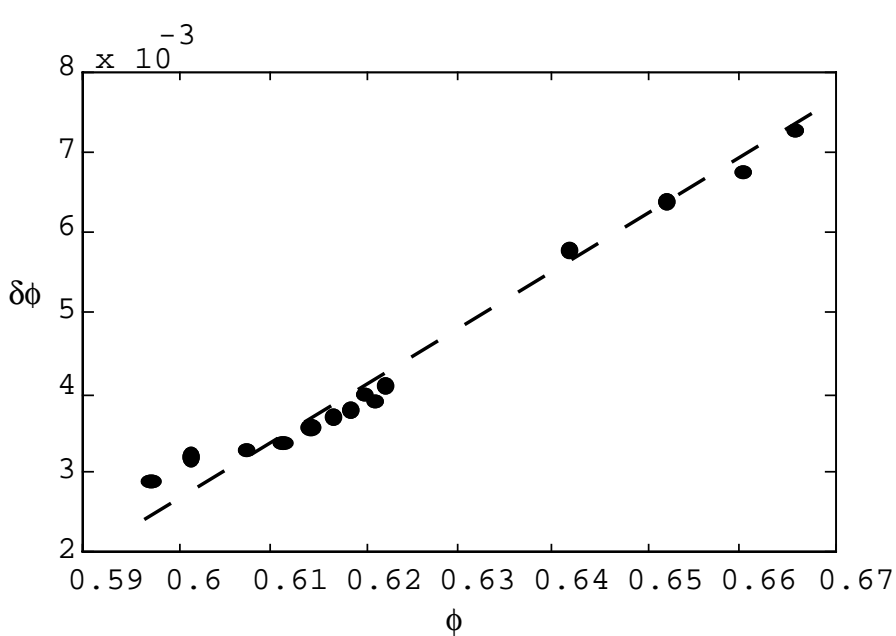

Figure 3. Amplitude of dilatation $\delta \phi$ versus volume frac$\operatorname{tion}^{\circ} \phi$.

-cles, 60000 in that case (typically a one week experiment with our setup).

The long-time volume fraction was well above the random-close packing value. We obtained a maximum volume fraction of $69.3^{\circ} \%$ to be compared to $63.66^{\circ} \%$ for a random-close packing. This means that crystalline arrangements are created during thre compaction. The crystal structure was observed at the wall of the shear apparatus, but we also checked that crystalline structures were present in the bulk of the packing by carefully removing the beads layer after layer at the end of an experiment. An example of crystalline structure is shown if figure 5, a photograph taken in the midst of the packing.

The time evolution $\phi(t)$ could not be fitted with an inverse logarithmic function as in Knight et al (1995) and the presence of ordered structure in our experiments may explain this difference.

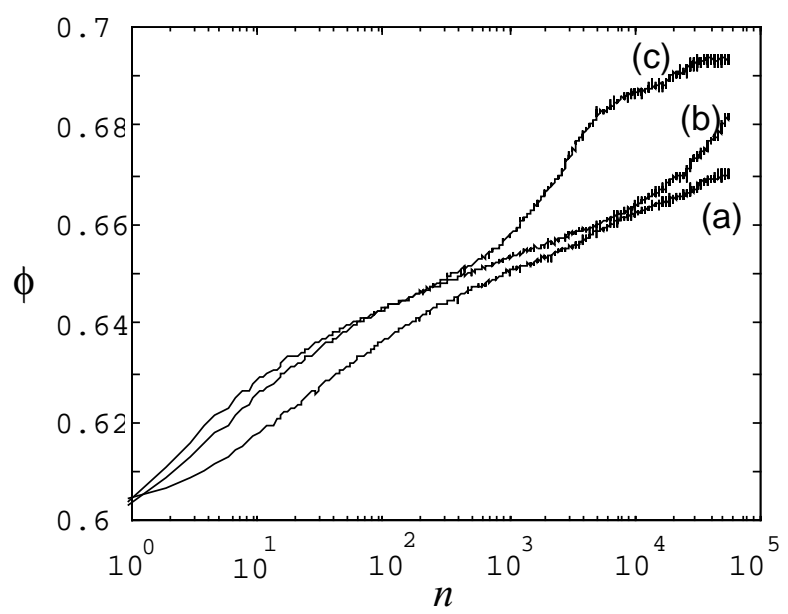

Figure 4. Long-time evolution for different shear angles : $\theta^{\circ}={ }^{\circ} 2.7 ;$ (a), $\theta^{\circ}={ }^{\circ} 5.4 ;$ (b), $\theta^{\circ}={ }^{\circ} 10.7 ;$ (c). 


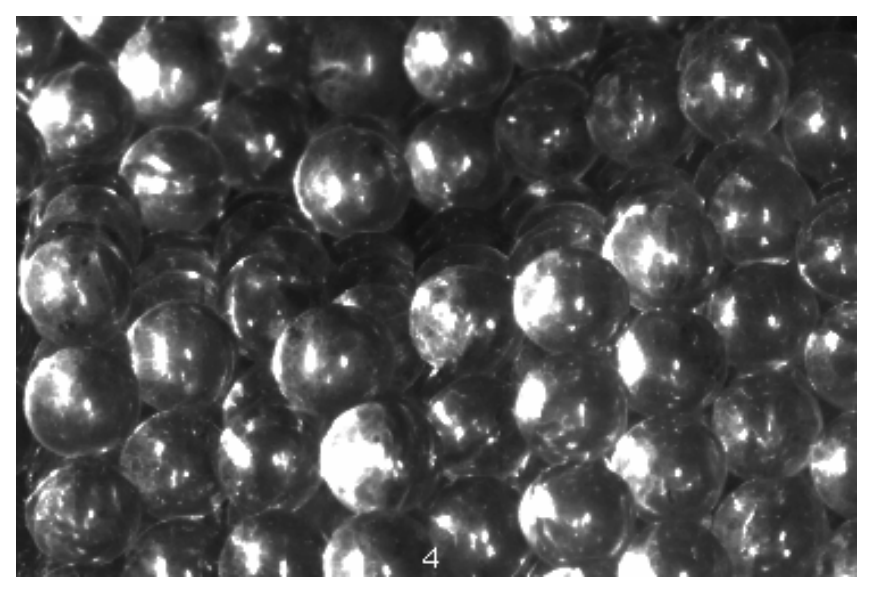

Figure5. Photograph of the packing in the bulk for $3 \mathrm{~mm}$ beads. Crystalline planes appear clearly, and are not connected with the boundary planes of the shear cell. Local arrangements of particles are face-centered cubic.

The response of the packing to a change of shear amplitude was also investigated. Increasing the shear angle produced a sudden decrease of the volume fraction whereas a decrease of shear angle produced a sudden increase of $\phi$. A linear relation between the angle change $\Delta \theta$ and the volume fraction jump $\Delta \phi$ was found (Nicolas et al 2000) : $\Delta \phi=-\alpha \Delta \theta$ with $\alpha={ }^{\circ} 1.45 \times 10^{-3}$ and $\Delta \theta$ in degrees.

Two kind of evolution have been observed: a slow and continuous compaction when the shear angle is constant and a rapid response when a change of angle is imposed. Moreover, the variation of the volume fraction $\Delta \phi$ induced by a sudden change $\Delta \theta$ of angle is independant of the state $\phi$ of the system. The rapid dynamic induced by an angle variation seems thus to be uncorrelated with the slow compaction dynamic.

\section{COMPACTION OF BIDISPERSE PACKINGS}

For these experiments, the granular matter was a mixture of $50^{\circ} \% 2^{\circ} \mathrm{mm}$ diameter beads and $50^{\circ} \%$ $3^{\circ} \mathrm{mm}$ diameter beads. The experimental procedure was the same as in the monodisperse experiments.

As in the monodisperse case, a rapid increase of volume fraction occured for the first 100 cycles (see figure ${ }^{\circ} 6$ ). But for the same shear angle, the maximum volume fraction $\left(65.5^{\circ} \%\right)$ is much lower in the bidisperse case. This lower volume fraction is easily explained by the fact that no order appeared during the shear process.

Compaction curves (M) and (B) are quite similar for the 1000 first cyles. After that time, the bidisperse curve does not evolve much, whereas the monodisperse curve increase up to $69^{\circ} \%$. It seems that the initial compaction $(n<1000)$ deals only with local re-arrangements of beads without creation of ordered structures. For later times, it seems that long-range arrangements of beads appear in the monodisperse case, and hence further compaction is possible. These long-range structures do not appear in the bidisperse case, and the packing is thus stuck into a random-close packing state.

Despite this difference with the monodisperse case, the bidisperse packing submitted to a sudden change of shear angle exhibited also a rapid compaction dynamic with a linear relation between $\Delta \phi$ and $\Delta \theta$.

\section{CONCLUSIONS}

We have shown that horizontal shear is responsible for compaction of a granular matter constituted of hard spheres. In the case of monodisperse beads, the highest volume fraction was $69.3^{\circ} \%$, and corresponded to a crystalline arrangement of the beads. No higher value could be obtained because of numerous deffects (grain boundary, dislocations) present in the bulk. In the case of a bidisperse medium (mixture of 2 and $3 \mathrm{~mm}$ beads), no crystalline structure was observed, but compaction occured with a volume fraction up to $65.5^{\circ} \%$.

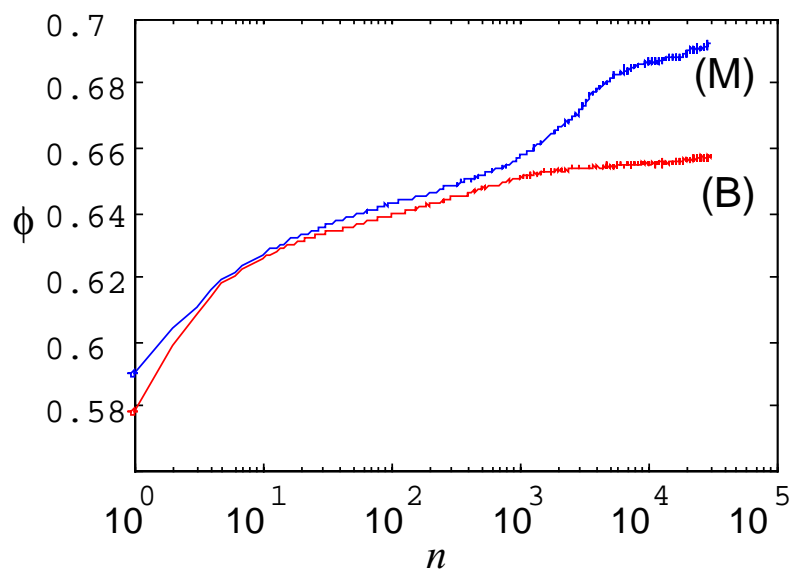

Figure 6. Volume fraction evolution for a monodisperse set of beads $(\mathrm{M})$ and a bidisperse set of beads (B). Shear angle was $\theta=10.2$ i

\section{REFERENCES}

Knight, J.B., Fandrich, C.G., Lau, C.N., Jaeger, H.M. \& Nagel, S.R. 1995. Density relaxation in a vibrated granular material. Phys. Rev. E 51 (5):3957-3963.

Nicolas, M., Duru, P. \& Pouliquen, O. 2000. Compaction of a granular material under cyclic shear. Eur. Phys. J. E 3:309-314

Nowak, E.R., Knight, J.B., Ben-Naim, E., Jaeger, H.M. \& Nagel, S.R. 1998. Density fluctuations in vibrated granular materials. Phys. Rev. E 57 (2):1971-1982.

Pouliquen, O., Nicolas, M. \& Weidman, P.D. 1997. Crystallization of non-Brownian spheres under horizontal shaking. Phys. Rev. Lett. 79:3640-3643.

Scott, G.D. \& Kilgour, D.M. 1969. The density of random close packing of spheres. Brit.J.Appl.Phys 2:863-866. 